\title{
A Study on the Connotation and Extension of Bank Resilience: Based on the Perspective of Active Risk Management
}

\author{
$\mathrm{Xin} \mathrm{Xu}^{1}, \mathrm{Lu} \mathrm{Lu}^{\mathbf{2}^{*}}$ \\ ${ }^{1}$ Department of World Economics and Politics, Jiangsu Administration Institute, Nanjing, China \\ ${ }^{2}$ Jiangsu Institute of Innovation and Development, Nanjing University of Finance and Economics, Nanjing, China \\ Email: ^lulu_altai@yahoo.com
}

How to cite this paper: $\mathrm{Xu}, \mathrm{X} ., \mathrm{L} \mathrm{Lu}, \mathrm{L}$. (2020). A Study on the Connotation and Extension of Bank Resilience: Based on the Perspective of Active Risk Management. Modern Economy, 11, 1141-1154. https://doi.org/10.4236/me.2020.116083

Received: April 28, 2020

Accepted: June 16, 2020

Published: June 19, 2020

Copyright $\odot 2020$ by author(s) and Scientific Research Publishing Inc. This work is licensed under the Creative Commons Attribution International License (CC BY 4.0).

http://creativecommons.org/licenses/by/4.0/

\begin{abstract}
The purpose of the research on bank resilience is to mobilize the initiative of banks in risk management. The negative impact of the financial crisis was been regarded as an opportunity to improve risk control ability to improve the banking industry's risk tolerance, self-healing ability and environmental adaptability in the financial market. This paper obtains the theoretical significance of bank resilience through concept definition and necessity analysis. Then, we analyze the form and process of bank resilience from dynamic and static aspects, respectively, makes it clear that how valuable bank resilience is to reform and characteristic development of the banking industry. Based on that, the factors influencing bank resilience analyzed and the risk management system is been reconstructed. Thus, the challenge of financial crisis to banks will transform into the opportunity to enhance bank resilience and realize the high-level balanced development of risks and benefits. The contribution of this paper is to introduce the concept of resilience into the financial field. Through the innovation of risk management mode, financial institutions are encouraged to carry out active risk management, so that banks can realize the diversification of operational risk business and improve the efficiency of risk control.
\end{abstract}

\section{Keywords}

Bank Resilience, Risk Management, Protective Factors, Resilience Reconstruction

\section{Background}

In banking industry, the traditional business philosophy is gradually shifting their trading mode regarding the bias of risk. Because in the present and future 
financial markets, with the diversification of financial products and the opening of financial markets, the degree of risk is increasing. Even state-owned banks cannot guarantee their survival from systemic risk contagion. Therefore, commercial banks should not only consider profit, but also consider risk-taking. Each risk shock in the market is a true test for a bank's risk management level. If the original model such as the indicator system and administrative guidance of the financial supervision department was been retained, the profit of the bank will be further suppressed in order to reduce the risk, which is obviously not conducive to the development of the bank. It is necessary to change the model of risk management and turn the passivity of risk management into initiative. By encouraging Banks to establish a risk control system based on their own business risk characteristics to cope with external risk shocks, and the existing risk control system should adjusted in each risk shock to increase the efficiency of Banks' risk management initiative and increase risk returns with strong risk tolerance. The meaning of the bank resilience generates under such a background, aiming to increase the confidence of the banking industry in coping with the financial crisis actively to improve the self-healing ability of risk loss and the adaptability of the new environment. In this way, the bank can rationally view the financial crisis, tap the potential risk management of the bank, turn the crisis into an opportunity, increase the competitive advantage in the constantly open financial market, and finally improve the profitability of the bank.

Compared with the existing research, this study has several academic contributions to the research of bank resilience. First, this paper starts from the essence of risk business of Banks and defines the characteristics, function process and value of resilience in the financial industry. Second, this paper upgrades the goal of bank risk management from maintaining short-term financial stability to realizing long-term financial stability by improving the efficiency of financial services. Third, this paper analyzes and compares the resilience of Banks at different levels, which makes clear the goal and provides effective methods for Banks to improve their risk control ability. The contribution of this paper is to introduce the concept of resilience into the financial field. Through the innovation of risk management mode, financial institutions are encouraged to carry out active risk management, so that banks can realize the diversification of operational risk business and improve the efficiency of risk control.

The remains of this study are organized as follows. First, we discuss the connotation of bank resilience. Next, we present a hierarchical analysis of bank resilience to active risk management functions. Finally, we discuss the research results and indicate possibly future research problems.

\section{The Connotation of Bank Resilience}

\subsection{The Definition of Bank Resilience}

\subsubsection{The History of Resilience}

Resilience, according to Webster's dictionary, is the ability to become stronger, healthier, and more successful after a negative event. The concept of resilience 
originated from physics, means that an object returns to its original state after under the press by external forces. Later, psychology adopted the meaning of "resilience" and extended it to include the ability of individuals to recover from setbacks and acquire new abilities to actively deal with external risks and challenges. Block, J. first proposed the concept of ego-resiliency in 1950. Since then, the study of resilience has experienced a leap from psychology to social science, economics and other fields. The research object of resilience has also expanded from the influence of children and adolescents' development to individuals or organizations in adversity, involving a range of influences from the experience of individuals and families to external factors of the system environment. According to the Human Development Report 2014, resilience is the backbone of any approach to secure and sustain human development. This action is the responsibility of the government and other institutions to protect the public, especially the vulnerable groups, to help them solve their own problems and reduce the risk sensitivity ${ }^{1}$. Individual development under stress of adversity varies, and the measure of resilience depends on the individual's adaptability and the degree of coordination with the external environment (Xi \& Zuo, 2014). When the resilience level of the society as a whole is improved, the average return of individual economy will exceed the expectation under the same risk bearing because of the positive economic externality.

\subsubsection{Literature Review (Related Work)}

Although the study of resilience was been applied in disaster prevention, psychology, urban development and other fields, the application of the concept in economic activities has not been widely spread. Moreover, previous studies mainly focus on the ability of developing countries to bear risk losses in the 2008 subprime crisis and recover from the crisis. Pontarollo \& Serpieri (2018) take the European Union as an example to show that the impact of the financial crisis on different countries in a certain region is asymmetric in time, power and speed, not all countries have experienced the same diffusion of financial risks. This is why, after the crisis, some regions quickly regained their pre-crisis levels of output and employment, while others fell into a long period of economic stagnation, and the recovery will be long and protracted. Countries with rapid economic recovery after the subprime mortgage crisis in 2008 include China, Australia and Latin America, which mainly rely on domestic sound banking system and macro prudent economic policies (Gregorio, 2013; Claessens et al., 2014). Bologna (2010) analyzed the macro policies that made the resilience of Australian banking system obvious from an international perspective. He believed that the banking system with resilience would still face various crises and risks, but

${ }^{1}$ In its Human Development Report 2014: Sustaining Human Progress: Reducing Vulnerabilities and Building Resilience, the United Nations Development Programme (UNDP) takes a fresh look at vulnerability and calls on countries around the world to strengthen the importance of resilience building, especially in poor areas and vulnerable groups. The report also argues that building resilience is not related to the level of economic development of countries, and that countries should strengthen their resilience systems. 
these risks would not threaten the stability of the system. At the same time, the positive role of Basel Accord in strengthening the resilience of banking system was been affirmed.

The financial system is a network structure with risk exposure. The role of resilience is to be able to bear risk losses or recover from losses when the financial system encounters a crisis (Bui et al., 2017). Regions with diversified economies are better able to resist external risks, which may relate to the fact that risk resistance factors such as innovation encouragement, reasonable economic system and entrepreneurship in local areas jointly increase the economic resilience of relevant regions (Sabatino, 2019). Abiad et al. (2012) defines resilience as the ability of developing economies to maintain long-term strong economic development, shorten and reduce the degree of economic recession, and achieve faster economic recovery. The key to strengthening the resilience of emerging markets and developing countries is a proactive economic policy and a good internal and external environment. In addition, factors such as the frequency of domestic and foreign economic shocks, specific policy measures, policy space and economic structure characteristics could all affect the duration of economic expansion, recession and recovery. The impact of these factors on financial institutions is a dynamic process, that is, there are differences in the role of resilience before, during and after the event. The role of resilience is to warn before the crisis, absorb risk loss when the crisis occurs, and recover and adapt to the new environment after the crisis (Conz \& Magnani, 2019).

\subsubsection{The Definition of Bank Resilience}

Based on the definition of resilience and the literature analysis of its organizational structure, combined with a series of financial reform measures made by the financial market after the financial crisis, we can get the definition of resilience of banks. Bank resilience is the positive factor utility generated by the interaction of internal and external protective characteristics of the bank, which can cope with the current risk when bank's stable operation state was been destroyed by the emergency. Through the adjustment and reconstruction of the protective factors, the bank can achieve a higher level of risk management ability and a long-term stable operation state.

\subsection{Connotation and Necessity Analysis of Bank Resilience}

The study on the resilience of the bank pays more attention to overall, forwardlooking and strategic management ability of the risks of the bank, as well as the long-term profitability of the bank and the balanced development process with future risks. Compared with the traditional banking theory, bank resilience has its unique focus. This section mainly analyzes the difference and necessity between the research on bank resilience and the previous research on bank risk management from the perspectives of the improvement of bank risk management, the adjustment of income structure, the efficiency of external supervision and the recovery of market confidence. 


\subsubsection{The Improvement of Risk Management Capacity Needs to Build Bank Resilience}

According to the risk society theory, modern society is a society that combines the instinct to take risks with the instinct to seek safety. While encouraging risk-taking with the spirit of financial innovation, the development trend of globalization spreads regional risks to all parts of the world at a faster speed, resulting in a faster spread of the financial crisis with a wide range of impacts and a more obvious butterfly effect on a global scale. For institutional investors, systemic risk not only brings higher expectations of financial returns, but also increases uncertainty about the future. When excessive risks break the equilibrium of the financial market and banking institutions fail to take advantage of resources and capabilities to realize the equilibrium, the sound development of Banks would destroyed and the financial rationing function of economic development will be weakened. Markman \& Venzin (2014) believe that the bank resilience with better effect should be composed of protective resources with high value, rare, difficult to imitate and irreplaceable, to ensure the long-term role of resilience and thus realize a virtuous cycle of bank operation.

\subsubsection{Banks Need to Build Resilience in Order to Adjust Their Income Structure}

The risk management of China's financial institutions mostly realized through external supervision, so Banks tend to pay attention to profit rather than risk control in the operation process. The single-target positioning mode makes the bank more vulnerable, which is not conducive to the improvement of the bank's risk control ability and the increase of long-term returns. The idea of resilience of Banks encourages them to think positively about the reasons for the weakening of the income structure, timely adjust the policies that are not conducive to risk supervision, and prevent the further aggravating of bank risks (Angeon \& Bbtes, 2015). The outbreak of the financial crisis exposed the fragility of the development of the banking industry. The development of finance is a process of constantly weighing risks and benefits. The expansion of the effective boundary of financial risk tolerance will expand the space for financial innovation, facilitate the formation of a richer portfolio of financial products, and achieve better risk management results. At the same time, China's economic development is the incomplete cycle and lacking of experience in the development and innovation of financial institutions in the economic downturn. Under the background of the current economic cycle, the research on the bank resilience is helpful to the formation of the operation rules of China's financial institutions in the economic recovery period.

\subsubsection{Less Effective External Regulation Requires Banks Building Resilience}

After the financial crisis, scholars generally believe that macro Prudential Financial supervision can inhibit the generation of systemic risk and the external contagion of risk, and effectively make up for the deficiencies of micro supervision. However, with the deepening of the market-oriented reform, the participation 
threshold of the financial market is lower, and the strength and operation quality of the financial machines participating in the competition in the financial market show great differences. Macro-prudential regulation only includes the construction of basic and unified indicators for the overall demand for financial development, which can ensure the stability of the operation of the financial market, but also limits the enthusiasm and flexibility of financial institutions in dealing with risks. The modern enterprise model of profit and loss makes the banking industry need to allocate resources to its own risks and benefits, and the resilience index constructed in the form of protective resource combination can enhance the ability of the bank to withstand external shocks. Different development histories and goals of Banks lead to different advantages and potentials in risk control. Therefore, Banks should adhere to the cultivation of Banks to adapt to environmental changes while following external regulatory indicators. The combination of government and non-governmental forces is conducive to improving the future development potential of bank resilience (O'neil et al., 2014). Only by actively mobilizing Banks' self-repair ability and environmental adaptability, can they improve their resilience and achieve the harmonious development of bank operation and financial environment.

\subsubsection{The Recovery and Strengthening of Market Confidence Need to Build Banks Resilience}

China's economic development has been on the rise, the financial development benefits from economic growth and is in a good state, the market shows excessive trust in financial institutions. When the economic cycle changes and the demand of China's economic reform double stimulate, the explosion of various risks of the banking institutions makes the market confidence appear a big gap. Together with the competition pressure of informal financial institutions, the market's trust in financial institutions further eroded. The introduction of the resilience theory changed the traditional idea that risk means loss. By showing financial market participants their sufficient resource advantages in resisting risks and losses, the market's tolerance for bank risks within a certain range was improved (Pratt, 2015). Banking has an inherent incentive to provide self-protection and self-repair. However, the explicit role of such factors needs to be recognized, stimulated, and be supported in the form of a combination of protective factors for risk management and reform and innovation in the banking industry. The concept of bank resilience provides a new system of evaluation criteria and indicators for the manifestation of protection factors and the adjustment of bank risk structure; it also provides a practical theoretical basis for the adjustment and reform of financial institutions in the period of economic downturn.

\section{A Hierarchical Analysis of Bank Resilience to Active Risk Management Functions}

The risk factors and protection factors of the bank form a process of mutual development. Whether it is the analysis of risk factors or protection factors, the 
actual focus is on how to choose the components of bank resilience to better play the self-protection ability of banking institutions and avoid or reduce the interference of bank risks. This paper explains the process of bank resilience to bank risk management from three aspects: the form of bank resilience, the formation of bank resilience and the reconstruction of bank resilience.

\subsection{The Form of Bank Resilience}

When the economy is in the upper stage, the behavior of controlling the risk of a single business within a certain range in order to maximize profits creates conditions for the accumulation of risks. The bank resilience enhance the judgment and self-repair ability of the bank through explicit or invisible effects. While improving the adaptability of the market, the bank make use of the operation rules of the market and its resource advantages to enhance its ability to predict the development of the financial market and to respond to the crisis. In this context, there are three main types of expression of resilience: the protective characteristics, ability and results of resilience. The protective trait form of resilience refers to the factors inherent in a bank that can play a protective role. According to the analysis of Garmezy model, the factors of resilience classifies into immune type, challenge type and compensation type, which respectively represent the adjustment of risk pressure, the challenge to risk and the compensation for the consequences of crisis. Risk types and market mechanisms influence the effect of protective factors, so the evaluation of protective factors needs to be under the same economic background and changes with the change of risk management objectives. The form of resilience (Figure 1) refers to the ability of banks to recover from the risk shock, to reorient the future business model and internal structure to meet the requirements of the new situation. Because the external environment caused by risk has changed, it is impossible for the bank's risk management model to continue the original model, then risk stimulates the bank's invisible protection factors to improve the combined effectiveness of risk control measures (Wójcik et al., 2018). Lindbom et al. (2015) believe that the key for Banks to withstand external shocks was the improvement of bank resilience. Therefore, in the process of protection factors and risk factors, Banks can constantly improve the organizational structure of resilience and improve the risk tolerance and management efficiency.

The result form of resilience refers to the bank's good adaptability under the influence of uncertain risks, and the bank's high resilience level be reflected through the effective management of various risks. Righi et al. (2015) analyze that some risks that lead to bank vulnerability generate profits and are inevitable. Therefore, it is a scientific way to take an effective way to manage such risks than to directly avoid them. Bank risk management that can deal with the crisis successfully and realize stable income will be the first choice of bank risk control.

Individual differences exist in the effect of Bank resilience, and Banks need to add new protective factors in time to adapt to the dynamic changes in the 


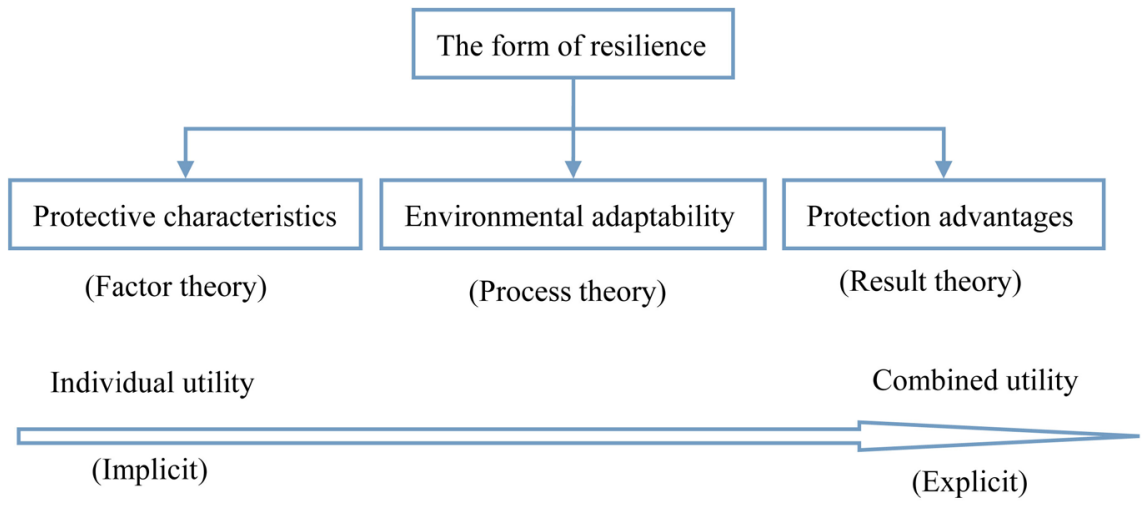

Figure 1. The form of resilience.

environment (Soni et al., 2014). The premise of resilience is the sense of crisis brought by emergencies, and the self-protection tendency of Banks will push them back to a stable state. Under the influence of the same crisis, the degree of impact between banks is different, the conditions for restoring stability are different, and the state of restoring stability may be different from that before the crisis. Therefore, the way to evaluate the resilience level of banks needs to analyze the ability of individual and environmental resources to coordinate development. In addition, this ability needs continuous running in and adaptation in order to achieve the long-term stable development of the bank, improve the bank's market image and market competitiveness.

\subsection{The Formation of Bank Resilience}

The impact of financial emergencies on risk factors and protection factors depends on facts, but it is inevitable to break the original equilibrium of Banks. The nature of the event is not necessarily negative, but it has a negative impact because it is not adapted to the market environment. Risk factors or protection factors can obtained from the external environment and internal of the bank to enhance its capacity, and the coordination and cooperation between factors of the same effect will determine the degree to which the bank's resilience enhanced. According to Xi \& Zuo (2014), the process of enhancing resilience is a process of hardening and a process of progressive development. In other words, the existing adversity experience can help individuals better adjust the allocation of resources and better deal with possible crises or stressful events in the future. Individuals gain experience through experience, develop coping skills, and improve their risk tolerance and control ability.

Ideally, the change in the proportion of reduced risk factors and increased protection factors would determine the level of increased resilience. In this paper, according to the level of bank's resilience, the resilience is divide into survival resilience, defensive resilience, reconfiguration resilience (Figure 2). Survival resilience is the primary bank resilience, that is, the level of bank resilience is not enough to impact the impact of emergencies, and the bank's earnings and stable operation ability are severely damaged. The bank's risk management 


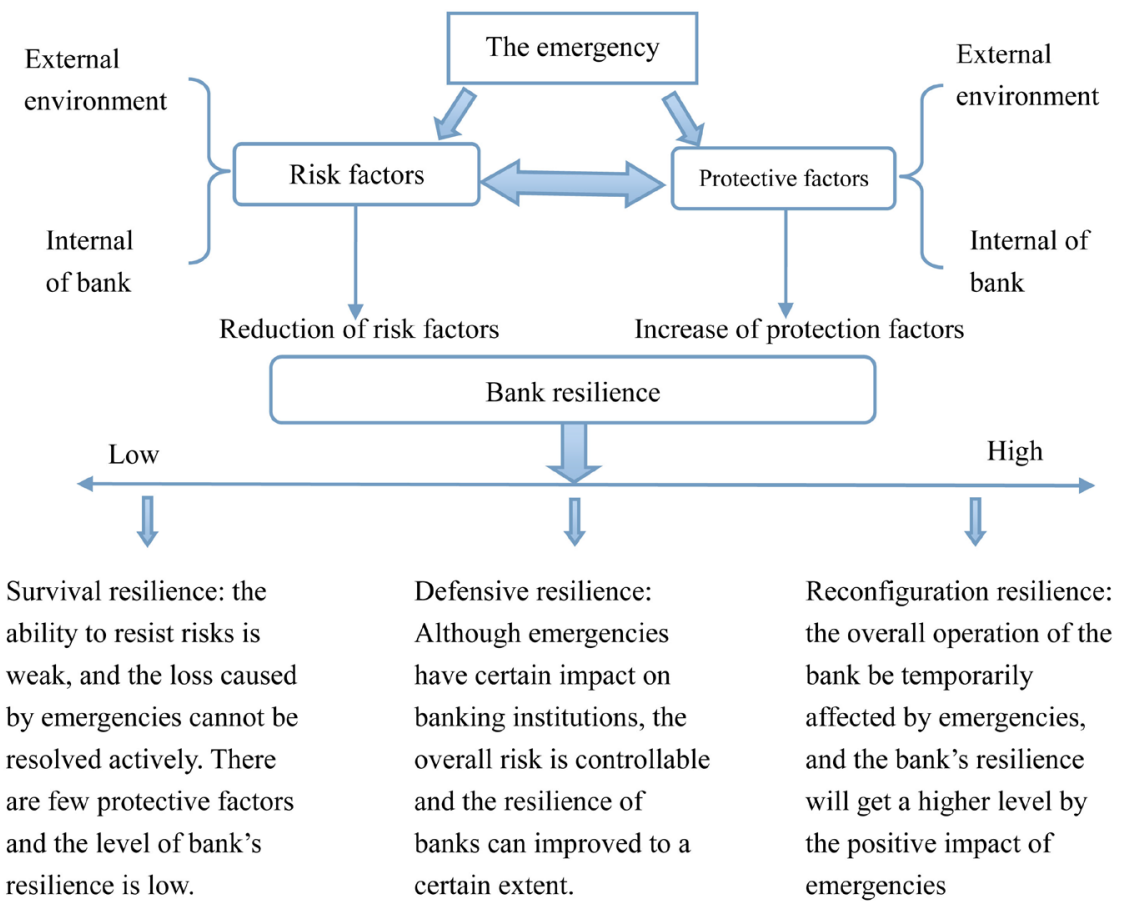

Figure 2. The formation of bank resilience.

belongs to the mode of passive risk taking. The effect of risk factors on Banks is far greater than that of protection factors, so the active protection ability of resilience is greatly limited. In the face of external shocks, the bank cannot adjust the risk management structure of the bank through active risk analysis to prevent the impact of financial risks on the bank in time. As far as the result is concerned, the defensive resilience can resist the risk impact and realize the controllable state of the overall risk of financial institutions. However, in the specific practice process, there are still some financial risks beyond the effective scope of the bank's risk management, which cannot provide the corresponding means of risk resistance to offset the possible risk losses when the risks occur, thus causing a certain negative impact on the stable operation of the bank. Therefore, the bank's understanding of risk is not enough, and the adaptability to the new financial environment needs to be further improved. The combination and effect of the bank's resilience can achieve a new leap on this basis, and achieve a higher level of risk management structure of the bank. Compared with the former two types of resilience, the reconfiguration resilience has the optimal effect. Banks with this level of resilience can choose appropriate protection factors to limit the actual losses caused by various risk factors. Through active risk prediction, dynamic adjustment of resilience combination can realized, and the pressure of emergencies can stimulate the corresponding protective characteristics of banks to play a role. Dynamic combination of resilience factors can realized according to the changes in the environment and the change of risk management objectives, to help the bank effectively resist the risk impact with the optimal protection ability. 


\subsection{The Factors Influencing the Reconstruction of Bank Resilience}

Referring to the framework of Kumpher model by Tian et al. (2011), the process analysis of bank resilience constructed as shown in Figure 3. This process takes the stress effect of the emergency as the original impact, and describes the resistance and reconstruction process of the bank institution under the influence of internal and external factors. In addition, under the interaction of risk factors and protection factors, it shows the forming process of differential resilience.

The reconstruction process of bank resilience is composed of two parts, one is the process of empirical resilience and the other is the process of innovative resilience reconstruction. The first thing to play a role after an emergency is the empirical resilience, which formed from the bank's historical experience and the existing risk management system. These risk control factors are the existing risk protection factors of the bank, some are the previous risk management experience of the bank, and some are the reserve of risk assets in accordance with the requirements of the financial supervision department. They are the assets or resources to resist the risks of the past crisis and to deal with the future risks. For example, in China's financial market, indirect financing is the main way of financing, so the risk supervision of financial institutions such as Banks is relatively strict, and the mode of supervision is very mature. Optional internal protection factors include management's decision-making power, brand image, risk control mechanism, business management advantages, etc. External protection factors include macro-prudential regulatory requirements, policy support, market environment, capital adequacy ratio, non-performing loan ratio, etc. However, for the non-deposit financial transactions formed in the financial innovation, such as securities business, trust and financial management business, the risk supervision of such transactions in the mode of managing the credit market will be much weaker. The different regulatory effects will encourage the market to carry out regulatory arbitrage, and the systemic risks caused by a large

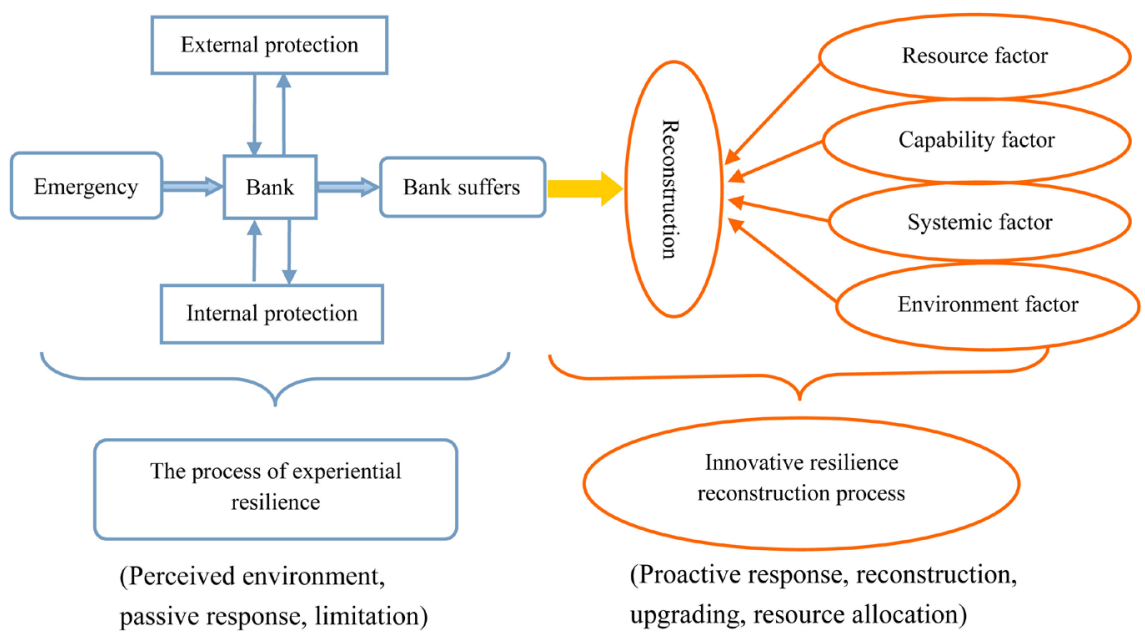

Figure 3. The process of bank resilience. 
amount of regulatory arbitrage will have a negative impact on every financial institution. Therefore, as the main body participating in market transactions, financial institutions need to add new protective factors into the risk control system according to the evolution of financial risks to constantly improve their ability to resist risks and quickly recover.

The meaning of innovative resilience is to adjust the risk control system actively by studying the new characteristics of risks in the internal and financial system of banks, to improve the ability of banks to resist the impact of external risks. The premise of innovative resilience is that empirical resilience cannot well buffer the negative impact of emergencies on banks. The existing combination of bank resilience becomes a sub optimal combination, which needs to add protection elements in the internal and external environment of the institution, and realize the process of strengthening resilience through new factor combination. In the process of innovative resilience reconstruction, the improvement of resilience of high-level Banks needs the dual elements of reconstruction and innovation, and Banks should choose their own risk control objectives and risk control strength. Fully consider the source of factors that may promote the improvement of resilience, such as its own advantages, market advantages and market expectations, and combine the new protection factors obtained through multiple channels with the bank's original advantages. The bank resilience reconstructed by the process of innovative resilience is hierarchical, and it is of no practical significance to compare different levels of resilience from a purely theoretical perspective. The advantages and disadvantages of resilience need to combine with the economic environment, the degree of social development and the resources and risk management ability of the bank at that time. Establish confidence in the face of crisis, adjust risk management plan with objectives, strengthen contact with relevant institutions and trading partners, and keep vigilance on market risk.

\section{Summary of Bank Resilience and Future Research Prospects}

One of the important reasons why resilience theory is applicable to many fields is that it represents a new developmental perspective. Every individual and organization will continuously improve their self-energy efficiency and absorb experience in dealing with risks and crises in the business process. The crisis pressure they encounter is an opportunity and challenge for them to achieve a higher level of development. The risk contagion and economic loss caused by the financial crisis is the explicit result of the uncoordinated development of stress factors and protection factors. Taking this opportunity, we can deeply understand the advantages and disadvantages of bank risk management, strengthen risk management, reduce the bank's vulnerability, and enhance the bank's ability to resist adversity. The study on bank resilience in this paper is still in the preliminary stage, and the following problems remain to be further study and analyze: 
1) The study on bank resilience is limited to the preliminary description of the phenomenon and the analysis of the causes, and the understanding of the forms and effects of bank resilience is not sufficient based on fully grasping the essence of resilience. It is necessary to construct an indicator system of bank resilience to guide the reform and upgrading of risk management system, and obtain the combination of protection factors of resilience level suitable for bank development, to reduce the potential loss of financial risk and reduce the uncertainty of bank practice.

2) The bank resilience always exists, but the analysis of the factors affecting the bank's resilience is not profound. At present, many articles focus on the security of the financial system from the perspective of bank vulnerability. Faulkner et al. (2019) believes that the study of bank vulnerability tends to describe in a negative way, and the relevant policy Suggestions are to mitigate the risks and negative effects caused by market interference. However, the positive effect on the interference ignored, so some factors that have a strong influence on the resilience of Banks have not been paid attention to. In the further study on the resilience of Banks, it is necessary to build an inclusive organizational structure and financial innovation mechanism to provide a more positive and explicit approach to the hidden protection factors.

3) There are different levels of bank resilience, and different levels represent different levels of risk management. Banks with different scale, business model and business characteristics need to choose appropriate resilience characteristics according to the characteristics of their own risk business. Thus, the assessment of different levels of resilience needs to combine with specific financial institutions and financial markets (Martin-Oliver et al., 2017). At the same time, the impact of risk management cost on regulatory efficiency also needs consideration. Therefore, the study on resilience of Banks is a comprehensive and comprehensive evaluation system.

4) The study on bank resilience in this paper is a preliminary attempt to introduce the definition of resilience into the financial industry. Rigg \& Oven (2015) believe that the resilience of Banks is as important to the development of Banks as the factors such as bank privileges, bank continuity and bank diversification. The current understanding of resilience in the financial sector is not deep enough. It is necessary to realize the integration of resilience and finance in the continuous theoretical and practical research, improve the risk management level of financial institutions, and realize the stable operation and benign development of the financial market.

5) The bank resilience theory is different from the traditional bank management theory in concept. In the process of practice, the coordinated or contradictory theoretical relationship of banks will affect the future development goals and business innovation of the banking industry. Therefore, it is necessary to skillfully and harmoniously integrate the bank resilience into the daily management activities of the banking industry, and establish a certain coordination mechanism between the bank's efficiency, bank innovation, bank supervision 
and other functional mechanisms, enhance the self-restraint and risk control capabilities of the banking industry and provide customers with more targeted and professional financial services, and establish a diversified and cross-disciplinary integrated intervention system and a market competition mechanism.

\section{Conflicts of Interest}

The authors declare no conflicts of interest regarding the publication of this paper.

\section{References}

Abiad, A., Bluedorn, J., Guajardo, J., \& Topalova, P. (2012). The Rising Resilience of Emerging Market and Developing Economies. IMF Working Paper, WP/12/300. https://doi.org/10.5089/9781475584851.001

Angeon, V., \& Bates, S. (2015). Reviewing Composite Vulnerability and Resilience Indexes:A Sustainable Approach and Application. World Development, 72, 140-162. https://doi.org/10.1016/j.worlddev.2015.02.011

Bui, C., Scheule, H., \& Wu, E. (2017). The Value of Bank Capital Buffers in Maintaining Financial System Resilience. Journal of Financial Stability, 33, 23-40.

https://doi.org/10.1016/j.jfs.2017.10.006

Claessens, S., Ghosh, S. R., \& Mihet, R. (2014). Macro-Prudential Policies to Mitigate Financial System Vulnerabilities. IMF Working Paper, WP/14/155. https://doi.org/10.5089/9781498319546.001

Conz, E., \& Magnani, G. (2020). A Dynamic Perspective on the Resilience of Firms: A Systematic Literature Review and a Framework for Future Research. European Management Journal, 38, 400-412. https://doi.org/10.1016/j.emj.2019.12.004

Faulkner, J.-P., Murphy, E., \& Scott, M. (2019). Rural Household Vulnerability A Decade after the Great Financial Crisis. Journal of Rural Studies, 72, 240-251. https://doi.org/10.1016/j.jrurstud.2019.10.030

Gregorio, J. D. (2013). Resilience in Latin America: Lessons from Macroeconomic Management and Financial Policies. IMF Working Paper, WP/13/259. https://doi.org/10.5089/9781475550214.001

Lindbom, H., Tehler, H., Eriksson, K. \& Aven, T. (2015). The Capability Concept-On How to Define and Describe Capability In Relation to Risk, Vulnerability and Resilience. Reliability Engineering \& System Safety, 135, 45-54.

https://doi.org/10.1016/j.ress.2014.11.007

Markman, M. G., \& Venzin, M. (2014). Resilience: Lessons From Banks That Have Braved The Economic Crisis-And from Those That Have Not. International Business Review, 23, 1096-1107. https://doi.org/10.1016/j.ibusrev.2014.06.013

Martín-Oliver, A., Ruano, S., \& Salas-Fumás, V. (2017). The Fall of Spanish Cajas: Lessons of Ownership and Governance for Banks. Journal of Financial Stability, 33, 244-260. https://doi.org/10.1016/j.jfs.2017.02.004

O’Neill, H. K., McCann, E. M., McLean, A. J., et al. (2014). One Message, Many Voices: Inter-Disciplinary Partnerships for Resilience Communication. Procedia Economics and Finance, 18, 400-407. https://doi.org/10.1016/S2212-5671(14)00956-3

Pontarollo, N., \& Serpieri, C. (2020). A Composite Policy Tool to Measure Territorial Resilience Capacity. Socio-Economic Planning Sciences, 70, 100669.

https://doi.org/10.1016/j.seps.2018.11.006 
Pratt, A. C. (2015). Resilience, Locality and the Cultural Economy. City, Culture and Society, 6, 61-67. https://doi.org/10.1016/j.ccs.2014.11.001

Rigg, J., \& Oven, K. (2015). Building Liberal Resilience? A Critical Review from Developing Rural Asia. Global Environmental Change, 32, 175-186. https://doi.org/10.1016/j.gloenvcha.2015.03.007

Righi, A. W., Saurin, T. A., \& Wachs, P. (2015). A Systematic Literature Review of Resilience Engineering: Research Areas and a Research Agenda Proposal. Reliability Engineering \& System Safety, 141, 142-152. https://doi.org/10.1016/j.ress.2015.03.007

Sabatino, M. (2019). Economic Resilience and Social Capital of the Italian Region. International Review of Economics and Finance, 61, 355-367.

https://doi.org/10.1016/j.iref.2019.02.011

Soni, U., Jain, V., \& Kumar, S. (2014). Measuring Supply Chain Resilience Using a Deterministic Modeling Approach. Computers \& Industrial Engineering, 74, 11-25. https://doi.org/10.1016/j.cie.2014.04.019

Tian, G. X., Qiu, W. J., \& Zhang, N. (2011). A Comparative Research about Five Kinds of Resilience Models in Contemporary West. Journal of East China University of Science and Technology (Social Science Edition), No. 4, 9-19.

United Nations Development Programme (2014). Human Development Report 2014: Sustaining Human Progress-Reducing Vulnerabilities and Building Resilience. New York: United Nations Development Programme.

Wójcik, D., \& Cojoianu, T. F. (2018). Resilience of the US Securities Industry to the Global Financial Crisis. Geoforum, 91, 182-194. https://doi.org/10.1016/j.geoforum.2018.02.035

Xi, J. Z., \& Zuo, Z. H. (2014). An Overview of Several Noteworthy Effects in Resilience Inquiry. Journal of Capital Normal University (Social Science Edition), No. 1, 115-123. 